\title{
Network Competence's Impact on Service Innovation Performance: Mediating Role of Relationship Learning
}

\author{
Zhaoquan Jian, Chen Wang, Xiande Zhao \\ School of Business Administration, South China University of Technology, Guangzhou, China. \\ Email: wangchenhymsn@126.com
}

Received May $9^{\text {th }}, 2013$; revised June $12^{\text {th }}, 2013$; accepted July $13^{\text {th }}, 2013$

Copyright (C) 2013 Zhaoquan Jian et al. This is an open access article distributed under the Creative Commons Attribution License, which permits unrestricted use, distribution, and reproduction in any medium, provided the original work is properly cited.

\begin{abstract}
In the unfolding knowledge-based economy, services do matter. But while they increasingly seem to play a pivotal role in innovation processes, there has been little systematic analysis of this role. Combined with the existing literatures, based on the service science theory, network competence theory and relationship learning theory, this paper analyzes the service innovation and the service innovation performance thoroughly. The paper constructs a structure equation model containing an intermediary variable. Through an empirical test of 243 enterprises of South China, this paper draws the following conclusions: 1) network competence has a positive impact on service innovation performance; 2) network competence has a significantly positive impact on relationship learning; 3) relationship learning has a positive impact on service innovation performance; 4) relationship learning plays a mediating role between the relationship of network competence and service innovation performance. This paper provides beneficial guidance for service innovation activities and strengthens the competitive advantage of service industry.
\end{abstract}

Keywords: Network Competence; Relationship Learning; Service Innovation Performance

\section{Introduction}

In the modern economy, the service industry has become an important engine of economic growth and a significant symbol for modernization. Services are no longer an "appendage” to manufacturing, but play a pivotal role in the economy of a country. International competitiveness in the future depends largely on the strength of the service edge, and the international trend of service industry will head many countries into more intense market competition. The shift to service as an economic driver is clear. The 2007 report by the International Labour Organization indicated that, for the first time in human history, worldwide service jobs (42\%) outnumbered jobs in agriculture (36.1\%) and manufacturing (21.9\%). While developed economies are dominated by the service sector, developing countries also start to assess their role in the service economy. If we take into account service activities in manufacturing, even the latest figures become an understatement. However, the importance of service has not attracted increased investment in service research and development. Indeed, despite the fact that the service sector accounts for over two thirds of GDP and jobs in many developed economies, investment in services represents less than one third of total R \& D spending [1]. This mismatch hinders the progress we could make to address many challenges.

The development course and experience of Japan and South Korea showed that, in the later stages of industrialization, the services sector occupied advantages and had a strong momentum of development, even contributed more to GDP, employment rate and environmental protection than industries. Since the Reform and Opening-up, China's services sector has made considerable progress, but there are still large problems in the internal structure and overall strength. After joining the WTO, China's services sector is facing unprecedented challenges and pressures. In the era of knowledge economy, only those enterprises, who adapt to environmental changes, adjust their business philosophy and shift from productoriented to service-oriented are able to survive. China's companies have no alternatives but to seize opportunities of service transformation and make a difference in service science and service innovation. It is possible to subvert the traditional manufacturing business model and achieve a breakthrough in the service-oriented manufacturing and e-commerce model. 
Ideas of service are, of course, not new. However, the scale, complexity and interdependence of today's service systems have been driven to an unprecedented level, due to globalization, demographic changes and technology developments. The rising significance of service and the accelerated rate of change mean that service innovation is now a major challenge to practitioners in business and government as well as to academics in education and research. A better understanding of service systems is required. Under the impact of the IT paradigm, networking has become the hallmark of the knowledge-based economy. Therefore, in today's increasingly competitive market homogeneity, the use of social network capital in service innovation has been considered an important way to provide additional revenue and profits, which has also become one of the forefront research subjects in domestic and overseas academics.

In the era of knowledge economy, the basis of value creation has gradually changed; the source of the enterprises to establish and maintain a competitive advantage has gradually focused its valuable, rare, inimitable, and non-substitutable knowledge resources, for the reason that many important innovative resources are usually not specific to an individual enterprise, but are scattered in the spread of the network in which different external partners have different resources or capacity [1]; enterprises can cross border integrating other resources of external partners to increase their own innovation and environmental suitability [2] to promote the cooperation efficiency and reduce transaction costs [3]. The development of organizational networking is to adapt to the changing environment, to reconstruct the internal power configuration and external market boundaries and to break the internal power structure of traditional hierarchical system and the trading relationship model with external competitors, suppliers, customers and other stakeholders, so as to truly create market value through the creation of knowledge.

The present study examines the impact of collaboration on service in the context of S-D logic and the resource-based-view (RBV). In contrast, prior studies have investigated the drivers of service innovation from the IT capability [4], dynamic capability [5], interorganizational relationships [6], network and environment [7], market drivers [8] and system [9] perspectives. Specifically, this study focuses on the impact network competence on service innovation in the context of China's economic transformation and service-based background. The results lend support to a positive relationship between network competence and service innovation. Our study expands upon prior network competence research and identifies network competence that involve network management task and network management qualifications in providing core capabilities will often lead to strategic benefits, particularly service innovation and new offerings. Also examined is the mediating role of relationship learning in influencing service innovation. Our findings have important theoretical and practical significance in providing useful guidance for the service sector's innovation activities, promoting service innovation capabilities and thus helping managers in collaborative businessto-business relationships to improve their network service innovation.

\section{Related Works and Research Hypotheses}

\subsection{Theory Foundation}

\subsubsection{Service Innovation Performance}

Adopted the DTI's broad definition, Innovation was "the successful exploitation of ideas, into new products, processes, services or business practices, and is a critical process for achieving the two complementary business goals of performance and growth, which in turn will help to close the productivity gap”. Economist Joseph Schumpeter, who contributed greatly to the study of innovation, argued that industries must incessantly revolutionize the economic structure from within, which was to innovate with better or more effective processes and products, such as the shift from the craft shop to factory. He famously asserted that "creative destruction is the essential fact about capitalism”. Innovation management has been an increasingly covered topic in scientific and management literature over the past 40 years. The reason for this interest was likely to be the realization that innovation was of key importance for survival of an organization. The need for innovation is imperative [10]. Or in Cooper's words, “its war: Innovate or die”. In addition, entrepreneurs continuously look for better ways to satisfy their consumer base with improved quality, durability, service, and price which come to fruition in innovation with advanced technologies and organizational strategies.

Many literatures on what made for successful innovations performance came from the New Service Development research field [11]. Service design practitioners also extensively discussed the features of effective service products and experiences. One of the key aspects of many service activities was the high involvement of the client/customer/user in the production of the final service. Without this coproduction (i.e. interactivity of service production), the service would not be created. This coproduction, together with the intangibility of many service products, caused service innovation to often take forms rather different from manufacturing innovation. In addition, although joint industry-university initiatives such as the Service Sciences, Management, and Engineering movement (led by scholars and practitioners from Cranfield University, IBM, and others) have recently embarked on the journey to put services-oriented 
research in a more prominent position, topics such as the performance measurement of service innovation projects remained under-researched in comparison to the advancements the research of product innovation has made [12]. Storey and Kelly [13] borrowed the concept of the Balanced Scorecard, and divided the metrics of service innovation performance into the individual project level and the overall program level. Adams et al.'s measurement model went more in depth into the seven measurement areas and proposed for each area several sub dimensions which were relevant for measuring before, during and after an innovation endeavor [14].

\subsubsection{Network Competence}

Attention to networks was powered by the notion that firms cannot survive and prosper solely through their individual efforts, and that each firm's performance depended upon the activities and performance of others. No business is an island. Co-operation with external partners will provide helpful if not necessary know-how and resources into a company's innovation processes. Hence, the nature and quality of the direct and indirect relationships that a firm develops with its counterparts is fundamental to managing in complex networks [15]. Knowledge of how to collaborate accumulates over time through experience, reflection, and interpretation [16]. Learning from collaboration was found in the empirical work reviewed to be a function of a firms' access to knowledge and its possession of the capabilities for utilizing the relationships and knowledge established. The evidence found in the review showed that a firm's competence of managing networks can differ substantially and networks can be shaped and designed to meet the firm's innovation needs.

The concept of network competencies and capabilities was derived (at least in part) from the Resource Based View (RBV) of the firm, a major pillar in the strategic management literature. We argue that the ability of a firm to develop and manage relations with key suppliers, customers and other organizations and to deal effectively with the interactions among these relations is a core competence of a firm —one that has a direct bearing on a firm's competitive strength and performance. This is referred to as a firm's network competence. Formally stated, a company's degree of network competence is defined as the degree of network management task execution and the degree of network management qualification possessed by the people handling a company's relationships. Hence, their definition seeks to include both having the necessary knowledge, skills, and qualifications as well as using them effectively. As such, network competence is a two-dimensional construct. Dimension one is task execution which can be further subdivided in a relationship-specific tasks and cross-relational tasks.
Dimension two concerns the qualifications whereby specialist and social qualifications are distinguished [17].

\subsubsection{Relationship Learning}

The concept of relational learning was first proposed by Selnes and Sallis [18], who held that in principle, relationship learning could be conceptualized in two different ways. The first way was to address the relationship as both a source and a target of organizational learning, which was consistent with the approach Lukas, Hult, and Ferrell [17] employed in developing a theoretical model for antecedents and consequences of organizational learning in marketing channels; the second way was to conceptualize relationship learning as a joint activity between suppliers and customers in which two parties shared information, which was then jointly interpreted and integrated into a shared relationship-domain-specific memory that changed the range or likelihood of potential relationship-domain-specific behavior. Relationship learning was thus a process to improve future behavior in a relationship. These two ways are essentially complementary.

Foil and Lyles believed that both enterprises and customers could find ways to reduce the invalid cost to improve relationship quality, market responsiveness and adaptability, and ultimately to enhance the innovation performance. Following the conceptualization of relationship learning developed by Selnes and Sallis [18], Li (2006) [19] proposed three different "sub-processes" of learning could occur between exhibitors and visitors in trade shows: relationship learning by sharing information, sense-making, and developing relationship-specific memories.

\subsection{Research Hypotheses}

\subsubsection{Network Competence and Service Innovation Performance}

The study assumed that innovation was both about the generation and exploitation of new products, processes, services and business practices. As products become increasingly modular and knowledge is distributed across organizations [20] firms recognize an increasing requirement to collaborate with other firms both formally and informally. Many scientific and technological breakthroughs result from numerous contributions of actors working in networks [21] and the standards necessary for a technology to function across different markets depend increasingly on networks of firms. Networking behaviour was identified as boosting the innovation output and competitiveness of firms in a diverse range of industries [22]. Industries on whose innovation networking has an identifiable impact included: service, primary, manufacturing and high-tech industries. 
The innovation benefits of networking identified by the literature include: obtaining access to new markets and technologies [23]; speeding products to market [24]; pooling complementary skills [25]. The evidence from the literature reviews also illustrates that those firms which do not cooperate or exchange knowledge would limit their knowledge base on a short-term basis and ultimately reduces their ability to enter into exchange relationships.

The network is a collection in which enterprises build relationships with their external partners to achieve a strategic goal; the relationship and network between those organizations are so complex that have to be managed effectively to promote the implementation of corporate strategic objectives [1]. The relationships between enterprises and different external partners affect each other, some relations will promote, while some could be conflicting. Therefore, enterprises must have the ability to manage different partnerships in order to integrate the embedded resources in different relations and fully play the comprehensive effectiveness of these resources to increase the likelihood of innovation success. However more generally, while the utility of networks for enhancing the development of innovations is well-established there appears to be a need for more focused research on the impact of networking on the development. There are similar studies in existing scholars which have made some achievements, for example Ritter and Gemunden built a new research model by regarding the corporate business strategy as antecedent variable of network and technical capacity and found that the network capacity had positive effects on innovation performance; Based on this, we propose:

H1: Network competence has positive impact on service innovation performance.

According to the operational definition of network capacity by previous scholars [1], if an enterprise has heavy network management tasks but low network management qualifications, while the other has low network management tasks but heavy network management qualifications, we say the two enterprises have the same network capacity, because network capacity is composed of network management and network management qualifications. However, this practice cannot in-depth understand the authenticity of the network capacity, and may even be misleading. The ability of organizational level and individual level are not invariably linked, or not completely complementary. This paper discusses respectively the impact of network management task and network management qualifications on service innovation performance, to truly understand the effect of asymmetric network capacity on service innovation performance. Therefore, we propose:

Hypothesis 1-1: Network management tasks have a positive impact on innovation performance.

Hypothesis 1-2: Network management qualifications have a positive impact on innovation performance.

In today's highly competitive society, only appropriate network relationship entails sharing more meaningful knowledge and technology, thus achieving a complex product or process innovation. Obviously, networking is the inevitable trend of development, and enterprises' sole choice is how to manage network relationship to promote information sharing and mutual learning, as well as to improve performance.

Specifically, the network capacity can be divided into tasks and qualifications, the former is compulsory task in managing company, the latter includes the qualifications, skills and knowledge necessary to perform tasks. Recent studies have confirmed the positive impact of network capabilities on organizational learning, inter-organizational information sharing and process innovation [1], this argument was also supported by cross-border studies. Given the relationship learning is a special form of organizational learning; this paper considers the enterprise's network capacity an important source of relationship learning. Based on this, we propose the following assumptions:

Hypothesis 2: The organization's network capacity has positive impact on relationship learning.

Hypothesis 2-1: The organization's network management tasks have positive impact on relationship learning.

Hypothesis 2-2: The organization's network management qualifications have positive impact on relationship learning.

\subsubsection{Relationship Learning and Service Innovation Performance}

Through relational learning, participants can find ways to improve the quality, reliability, speed of the information transmission and knowledge-sharing. Chen, Lin, and Chang [26] found that relational capital had a positive impact on new product development performance, among which relationship capital referred to the relationship between enterprises, upstream suppliers, downstream distributors, strategic partners and other outside shareholders. Information sharing is an important dimension of the relationship learning among members. In order to promote innovation, enterprise can learn from its partners, customers and suppliers through learning relationship. Many scholars have increasingly recognized the relationship learning in the network relations is an important way to improve the competitiveness [19].

Performance refers to the accomplishment of a given task measured against preset known standards of accuracy, completeness, cost, and speed. Cannon and Perreault [27] deemed that the exchange of information between buyers and sellers would improve the customer 
value provided by the seller performance [27]. Similarly, Selnes and Sallis' research [18] pointed out that relationship learning had a positive effect on relationship performance. In recent years, due to increasingly blurred boundaries of the industrial and service sectors, manufacturing had become more dependent on the realization of the value-adding in service elements and the establishment of competitive advantage, Grönroos [28] even believed that all businesses were services, so in the study of service innovation, there was no need to distinguish whether it occurred in service sector or manufacturing company. In the study of service innovation, we should focus on the information, processes, and interactive levels, and put more emphasis on social interaction factors in the process of innovation. Accordingly, we propose the following assumptions:

Hypothesis 3: The relationship learning has a positive impact on service innovation performance.

\subsubsection{Network Capacity, Relationship Learning and Service Innovation Performance}

Establishing relations with key customers and suppliers is essential for enterprises. On the essence relationship learning means organization acquire, share and pass each other important information through a close partnership, thus to create valuable knowledge. An organization must first develop a specific network relationship, get some sort of network status and complete the network tasks, which will entail continuous learning activities. Based on organization's learning theory, organization can create the exchange and integration of knowledge through personal interaction, and thus forming collective cognition and organizational memory, and providing the impetus for future innovation [29]. Organizational memory is an organization's preservation and accumulation of past experience [30]; on the one hand, it's the result of learning, on the other hand, it will affect the follow-up learning activities and innovation. During organizational learning process, the memory storages as future learning test, contribute to the accumulation of organizational knowledge and the construction of organizational learning capability. Similarly, Johnson and Sohi [17] found that the relationship memory, namely the shared collective information through long-term interaction and cooperation, would be stored in "memory" of both partners between the partner organizations, and influence the future interaction behavior and relationship quality, thereby affecting the cooperation performance. In summary, it is not difficult to find the level of organizational networking capability has impact on the relationship learning ability, while the relationship learning will affect future longterm interaction and cooperation through the "memory" accumulated by the organization interaction, thereby affecting innovation performance. Accordingly, this paper presents:

Hypothesis 4: Relationship learning moderates the relationship between network capacity and service innovation performance.

\section{Research Design}

\subsection{Research Framework}

Based on previous research findings, interviews and group discussions, the research framework model shown in Figure 1 is developed.

\subsection{Variable Definitions and Measurement}

Informants were told that the purpose of the survey was to investigate state of the business practices. Independent sample t-tests for differences between means of the key variables were conducted to check for non-response bias. Tests were performed between early and late respondents. As per convention [31], it is postulated that the late respondents are relatively dis-interested respondents, similar in nature to non-respondents. All t-tests indicated an absence of significant differences between the means at a $p<0.01$ level of significance. Thus, by this measure, the sample appears to be relatively free from nonresponsive bias.

To avoid cultural bias and ensure validity, the Chinese version was back-translated into English, and we paid special attention to detecting any misunderstandings that might arise due to translation. The questionnaire was further pretested with 30 high-tech enterprises. Items that were identified as being problematic were revised or eliminated. The research modified and consummated the questionnaire through the detection of internal consistency quotient of the questionnaire's subjects, single subject reliability analysis and KMO value. This study measures questionnaire by using 5 -point Likert scale.

1) Network Capacity. This article refers network capacity to enterprises' ability to improve their network status and deal with specific network relationship. The scale measuring network competence is divided into two dimensions of task implementation and qualification, and a total of 11 question items.

2) Relationship Learning. Based on Slater and Narver's [32] perspective of organizational learning program, the relationship learning is defined as: inter-organizational sharing, common understanding of market

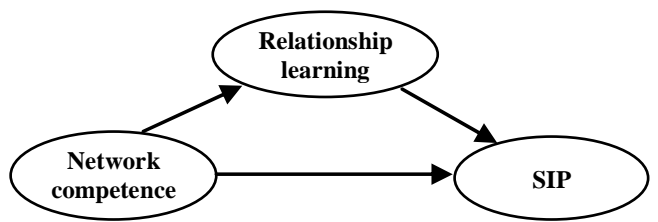

Figure 1. The research model. 
information, and the spread of knowledge. This study identifies the relationship learning a multi-item measure that comprises the following sub-constructs: information sharing, information dissemination and common understanding, with a total of 10 questions.

3) Service Innovation Performance. Synthesizing the research result from Storey and Kelly [13], combined with the new scale standard with the characteristics of service innovation, the research selects 6 indexes such as finance performance, customer performance, internal performance.

\subsection{Research Samples}

This study analyzes data at the firm level. Both the sample and the variables used in this analysis came from the Pearl River Delta of China firms' survey. The sample was representative of the population of high-tech firms of the Pearl River Delta, because the sampling frame was generated by a random sampling process. From July 2010 to January 2011, we received 292 questionnaires of the 485 copies distributed, with a total recovery rate of $60.2 \%$. Removing 49 invalid questionnaires, valid questionnaires were 243 and the final valid return rate was $50.1 \%$. Questionnaire distribution and collection was mainly taken in four different ways: The first way was through the Yellow Pages and mentor business cards recorded by e-mail questionnaires. In this way, in a total of 172 questionnaires, 110 were recovered with the recovery rate of $64.0 \%$; and 79 valid questionnaires were recovered with the valid return rate of $45.9 \%$. The second way was through the personal distribution by one of the authors to the relevant companies. In this way, all of the 10 questionnaires distributed were returned with the return rate up to $100 \%$, and all of which were valid. The third was that the author brought the paper questionnaires to the classroom of a Master of Engineering to release, and required the on-site filling and on-site recycling on the part of respondents. 93 of 116 questionnaires were recovered with a recovery rate of $80.2 \%$; and 77 valid questionnaires were recovered with the valid return rate of $66.4 \%$. Lastly, we distributed the questionnaires through a personal relationship network. In this way a total of 87 questionnaires were issued, with $88.5 \%$ returned, and all of which were valid.

The structure of the sample firms is sufficiently diverse and heterogeneous: 1 ) Industry categories: $19.3 \%$ in manufacture industry, $16.5 \%$ in professional, scientific and technical industries, $11.9 \%$ in the finance and insurance industry, $14.0 \%$ in wholesale and retail, $7.0 \%$ in construction industry, $3.3 \%$ in the culture, sports and leisure industry, $6.2 \%$ in the optoelectronics industry, $5.8 \%$ in logistics, transportation and warehousing services, and $16 \%$ in others; 2) Capital sum: less than 10 million Yuan (RMB) accounted for 36.2\%, 10 million to
50 million Yuan accounted for $13.6 \%$, 50 million to 100 million Yuan accounted for $7.4 \%, 100$ million to 500 million Yuan accounted for 9.1\%, 500 million to 1 billion Yuan accounted for $10.7 \%$, more than 1 billion Yuan accounted for 23.0\%; 3) Number of employees: $33.3 \%$ have less than 100 employees, $11.1 \%$ have 101 to 200 employees, $15.2 \%$ have 201 to 500 employees, 9.5\% have 501 to 1000 employees, and $30.9 \%$ have more than 1000 employees.

\subsection{Reliability and Validity of the Samples}

In this article, the consistency coefficients of network capacity, relationship learning and service innovation performance are $0.869,0.833$ and 0.862 respectively. Cronbach's Alpha was used to assess the reliability of each measures. Items were eliminated from their respective scales if resulted in a higher Cronbach's Alpha. The Alpha of all scales exceeded the cut-off of 0.70 as shown in Table 1. The items were then factor analysed to check for their convergent and discriminant validity. All items of scales should load strongly on a single factor to demonstrate convergent validity and load weakly on other factors to demonstrate discriminant validity. Results provided evidence of convergent and discriminant validity.

This article used exploratory factor analysis (EFA) and confirmatory factor analysis (CFA) to examine the content validity and construct validity of measurement tools, and did exploratory factor analysis on network capabilities, relationship learning and service innovation performance. Table 2 showed that the KMO values of the

Table 1. Coefficient of crohbach's $\alpha$.

\begin{tabular}{|c|c|c|c|}
\hline & Factors or Variables & \multicolumn{2}{|c|}{ Cronbach's $\alpha$} \\
\hline \multirow{2}{*}{$\begin{array}{c}\text { Network } \\
\text { capacity (11) }\end{array}$} & Network management task (5) & \multirow{2}{*}{0.869} & 0.842 \\
\hline & Network management qualification (6) & & 0.856 \\
\hline \multirow{3}{*}{$\begin{array}{l}\text { Relationship } \\
\text { learning (9) }\end{array}$} & Information sharing (3) & \multirow{3}{*}{0.833} & 0.910 \\
\hline & Information dissemination (3) & & 0.748 \\
\hline & Common understanding (3) & & 0.751 \\
\hline \multicolumn{2}{|c|}{ Service innovation performance (6) } & \multicolumn{2}{|c|}{0.862} \\
\hline
\end{tabular}

Table 2. KMO and bartlett test.

\begin{tabular}{|c|c|c|c|}
\hline KMO and Bartlett Test & $\begin{array}{l}\text { Network } \\
\text { capacity }\end{array}$ & $\begin{array}{l}\text { Relationship } \\
\text { learning }\end{array}$ & $\begin{array}{c}\text { Service } \\
\text { performance }\end{array}$ \\
\hline $\begin{array}{l}\text { Kaiser-Meyer-Olkin Measure } \\
\text { of Sampling Adequacy }\end{array}$ & 0.843 & 0.768 & 0.867 \\
\hline $\begin{array}{l}\text { Appropriate } \\
\text { Chi-square }\end{array}$ & 1178.463 & 1009.278 & 612.246 \\
\hline Test of degrees of freedom & 55 & 36 & 15 \\
\hline $\begin{array}{l}\text { significance } \\
\text { probability }\end{array}$ & 0.000 & 0.000 & 0.000 \\
\hline
\end{tabular}


three items were $0.843,0.768,0.867$, Bartlett sphericity test showed the significance probability is $0.000\left({ }^{* * *}\right)$, indicating that next step of factor analysis can be continued.

As to the validity, the question items in this study were all from published literatures and a lot of scholars have also used these scale tables to measure related variables. We modified the questionnaire by consulting and pretesting to confirm final questionnaire. Therefore, this questionnaire ought to have good content validity and reach the requisite validity construct. However, considering the cross-culture factors, this study would continue to use the verifiable factors to examine each scale's construct validity (see Table 3 ). Thus, we got the conclusion that the indicator CFI, GFI, RMR and RMSEA were all acceptable. Finally, multicollinearity was determined by examining the variance inflation factors (VIF) for each of the regression coefficients. All of the VIF scores were well below the cut-off of 10, "suggesting that multicollinearity was not a likely threat to the substantive conclusions drawn from the parameter estimates.”

\section{Results}

After the construct validity analysis of the sub-scales, prior to structural equation analysis, we first investigate the correlation of the variables in order to reveal the strength of the statistical relationships between variables, and provide a basis to further depict and reflect the change of variables. Table 4 contains the means, standard deviations, correlations used in the study.

\section{Structural Equation Model Analysis}

To illustrate the impact of two sub-dimensions of network management tasks and network management qualifications in network capacity on relationship learning and service innovation performance (SIP), as well as the mediating variable of relationship learning (RL), we particularly establish a first-level intermediate model containing sub-dimensions of network capacity. Tables 1-3 indicate the acceptable reliability and validity of each variable, so using the single measurement indicator instead of multiple measurement indicators is available. Therefore, this paper takes the average score of the firstlevel factors' measurement item as the value of the factor, which is later conducted as the multiple measurement indicators of the second-level variables. For example, when the network capacity is the latent construct, the observed variables will be network management task (NMT) and network management qualification (NMQ), then the number of measurement indicators can be reduced effectively. Following the model, we use the Structural Equation Models (SEM) to analyze the interrelationship among these variables, associated with the
Table 3. Confirmatory factor analysis.

\begin{tabular}{cccccccc}
\hline Goodness of fit & $\chi^{2} / d f$ & GFI & CFI & TLI & RMR & RMSEA & NFI \\
\hline $\begin{array}{c}\text { Network } \\
\text { capacity }\end{array}$ & 1.204 & 0.963 & 0.978 & 0.968 & 0.026 & 0.031 & 0.925 \\
$\begin{array}{c}\text { Relationship } \\
\text { learning }\end{array}$ & 1.816 & 0.970 & 0.986 & 0.971 & 0.028 & 0.072 & 0.934 \\
$\begin{array}{c}\text { Service } \\
\text { innovation } \\
\text { performance }\end{array}$ & 1.778 & 0.916 & 0.958 & 0.902 & 0.046 & 0.076 & 0.945 \\
\hline
\end{tabular}

Table 4. Descriptive statistics and correlation matrix.

\begin{tabular}{ccccccccc}
\hline & 1 & 1.1 & 1.2 & 2 & 2.1 & 2.2 & 2.3 & 3 \\
\hline 1 & 1 & & & & & & & \\
1.1 & $0.843^{* * *}$ & 1 & & & & & & \\
1.2 & $0.862^{* * *}$ & $0.453^{* *}$ & 1 & & & & & \\
2 & $0.702^{* *}$ & $0.608^{* *}$ & $0.590^{* *}$ & 1 & & & & \\
2.1 & $0.429^{* * *}$ & $0.357^{* *}$ & $0.375^{* *}$ & $0.763^{* * *}$ & 1 & & & \\
2.2 & $0.611^{* *}$ & $0.530^{* *}$ & $0.512^{* *}$ & $0.778^{* * *}$ & $0.348^{* *}$ & 1 & & \\
2.3 & $0.606^{* * *}$ & $0.541^{* * *}$ & $0.494^{* *}$ & $0.775^{* * *}$ & $0.344^{* *}$ & $0.496^{* *}$ & 1 & \\
3 & $0.646^{* * *}$ & $0.556^{* *}$ & $0.546^{* *}$ & $0.684^{* *}$ & $0.462^{* *}$ & $0.529^{* *}$ & $0.604^{* *}$ & 1 \\
Mean & 3.78 & 3.87 & 3.71 & 3.67 & 3.51 & 3.74 & 3.75 & 3.76 \\
SD & 0.68 & 0.80 & 0.73 & 0.68 & 0.69 & 0.79 & 0.68 & 0.60 \\
\hline
\end{tabular}

statistics software AMOS17.0 The theoretical model of this paper is shown in Figure 2, with latent variable demonstrated by ellipse and observed variable demonstrated by rectangle.

The main goodness-of-fit indexes are shown in Table 5. In the table, we know the value of $\chi^{2} /$ d.f. is 1.929 which is less than 5.0 , while the value of CFI is 0.931 which is more than 0.9, the values of RMR, AIC and ECVI are less than the values of saturated model and independence model which meet the evaluation criteria of the index. Every fitting index reaches the acceptable criteria in SEM. The measurement model fits the data satisfactorily. Therefore, the model does not have to be modified.

According to the statistic analysis, hypothesis 1 to 4 gain the support, That is, the two sub-dimensions of the network capacity have direct positive impact on relationship learning, among which network management task has a distinct direct positive impact on relationship learning ( $p<0.001)$; network management qualification has a distinct direct positive impact on relationship learning $(p<0.001)$; relationship learning has a distinct direct positive impact on service innovation performance $(p<$ $0.05)$; the two sub-dimensions of the network capacity have direct positive impact on service innovation performance, among which network management task has a distinct direct positive impact on service innovation per- 


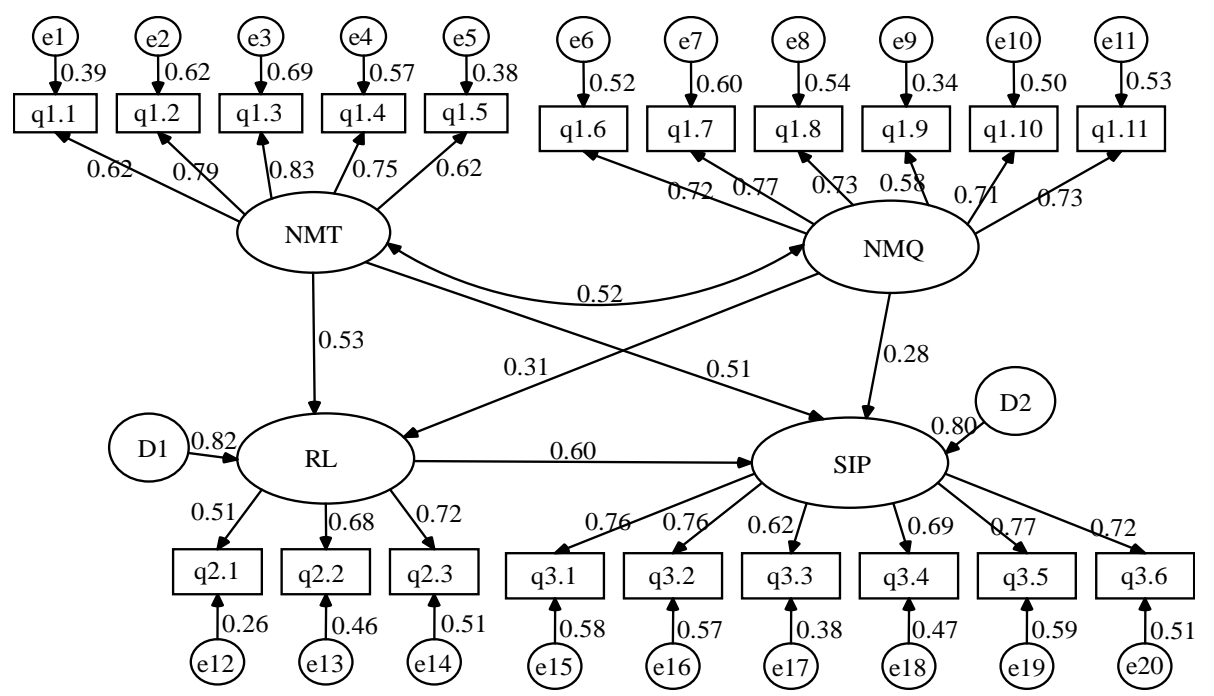

Figure 2. The theoretical model of this paper.

Table 5. Goodness-of-fit index of first-order mediate model.

\begin{tabular}{ccccc}
\hline Goodness of fit & $\chi^{2} / d f$ & CFI & RMSEA & AIC \\
\hline Criteria & $<5$ & $>0.90$ & $<0.08$ & small \\
Default model & 1.929 & 0.931 & 0.062 & 448.385 \\
Saturated model & - & 1.000 & - & 460.000 \\
Independence model & 11.575 & 0.000 & 0.209 & 2470.741 \\
\hline
\end{tabular}

formance $(p<0.05)$; network management qualification has a distinct direct positive impact on service innovation performance $(p<0.05)$.

\section{Conclusions and Implications}

With literature review and case interview, this paper constructs the theoretical model and studies the correlation among network capacity including network management task and network management qualification, relationship learning and service innovation performance. Choosing the 243 samples from 10 high-tech firms in Pearl River Delta of China, we have gained some valuable findings.

\subsection{To Establish an Enterprise Innovation Network Focusing on Both Quality and Quantity}

The network members include customers, suppliers, competitors and government departments. Network capacity is a cross-relationship management capability, with which companies can obtain information and location advantages, avoid and resolve conflicts, and ultimately improve the level of business innovation. The network capability is enterprises' network management qualification and executive ability of dealing with external organizations. Classified regulation is to be carried out for enterprises, which start from industry characteris- tics and its location in the industry chain, focusing on selected partners, customers and suppliers to establish long-term, deep and cooperative relations. Given the limited resources, the enterprises should first pay attention to the most important partners, customers and suppliers, and grasp the connection strength. The nature of the network capacity is trust; therefore, enterprises must first establish trust with partners, improve information exchange and share capabilities between partners, as well as communicate openly and frequently. Openness of communication means that both sides should maintain the timely share of information through formal or informal channels; disclose the important matter of programs, such as projects, expectations and goals to each other, and eliminate habitual defensive behavior, so as to maintain fully and timely grasp of all aspects of the partners to reduce the risks of asymmetric and incomplete information.

\subsection{The Enterprise That Focuses on Learning Can Live Long}

Knowledge is the most important resource for companies to create added value, so organizations must think about how to create knowledge advantage. Organization can access knowledge not only through experiential learning, internal creation and market trading mechanisms, but also can take advantage of the inter-organizational relationship, so learning is not limited to the activities within organization. Thus learning theory plays a very important role in the theory of competitive advantage, and the academic study of organizational learning has gone on for over 40 years. Previous research on knowledge management mostly take a perspective from organizational learning to explore the creation and application of knowledge, while the inter-organizational learning is rarely mentioned, which particularly stresses on enhanc- 
ing the learning ability through partnerships between organizations, and is also called relational learning [33]. Through relational learning, it is not difficult to find that, for the suppliers, interactive learning with dealers and customers can better understand customer needs, improve product quality and design, and develop products and services to better meet customer demand; while for the dealers, through the process of interaction with suppliers (such as training, regular meetings, etc.), learning order optimization, product design, marketing programs, and delivery processes to achieve the purpose of cost reduction. Relational learning can contribute to the coordination of suppliers and distributors, and is conducive to the establishment and maintenance of long-term trade relations to maximize the whole benefits. As sustainability becomes an increasingly urgent global concern, businesses should take the opportunity to expand the definition of relationship learning to include new measures. More emphasis should be placed on the balance between efficiency, effectiveness and sustainability. Roadmaps for service innovation should include updated performance measures and adjust mechanisms of measurement. Only when an enterprise continuously learn and absorb knowledge from its relationship network, can it survive in the competitive environment and continue to grow.

\subsection{Limitations and Future Research Directions}

There are several limitations with the study. First, the cross-sectional nature of the data does not permit us to determine whether service innovation performance has actually achieved. Although network management task and management qualification are useful proxies for network performance, future research may consider improving measures in this area. The response rate is also a major limitation of the study, as discussed earlier, and should be taken into account in interpreting the results. Clearly the key items measure the perceptions of one key informant, at a specific moment in time. Given this, it would be revealing to determine an organization's current level of this key construct, and then track any changes with use of a longitudinal study. This would provide us with a much clearer picture of the nature of relationship learning, how it evolves over time, and more specifically, how it manifests itself.

\section{Acknowledgements}

This paper is supported by the research funds from National Natural Science Fund of China (71272132; 71090 403/71090400).

\section{REFERENCES}

[1] H. G. Gemünden, T. Ritter and P. Heydebreck, “Network and Innovation Success: An Empirical Analysis in German High-tech Industries,” International Journal of Research in Marketing, Vol. 13, No. 4, 1996, pp. 449-462. http://dx.doi.org/10.1016/S0167-8116(96)00026-2

[2] A. Capaldo, "Network Structure and Innovation: The Leveraging of a Dual Network as a Distinctive Relational Capability,” Strategic Management Journal, Vol. 28, No. 4, 2007, pp. 585-608. http://dx.doi.org/10.1002/smj.621

[3] J. Nahapiet and S. Ghoshal. "Social Capital, Intellectual Capital, and the Organizational Advantage," Academy of Management Review, Vol. 23, No. 2, 1998, pp. 242-266.

[4] J. S. Chen, H. T. Tsou and Y. H. Huang, "Service Delivery Innovation: Antecedents and Impacts on Firm Performance,” Journal of Service Research, Vol. 12, No. 1, pp. 36-55. http://dx.doi.org/10.1177/1094670509338619

[5] R. Agarwal and W. Selen, "Dynamic Capability Building in Service Value Networks for Achieving Service Innovation.” Decision Sciences, Vol. 40, No. 3, 2009, pp. 431475. http://dx.doi.org/10.1111/j.1540-5915.2009.00236.x

[6] A. B. Eisingerich, G. Rubera and M. Seifert, "Managing Service Innovation and Interorganizational Relationships for Firm Performance: To Commit or Diversity?” Journal of Service Research, Vol. 11, No. 4, 2009, pp. 344-356. http://dx.doi.org/10.1177/1094670508329223

[7] R. P. Lee, G. O. Ginn and G. Naylor, "The Impact of Network and Environmental Factors on Service Innovativeness," Journal of Service Marketing, Vol. 23, No. 6, 2009, pp. 397-406.

http://dx.doi.org/10.1108/08876040910988183

[8] L. L. Berry, V. Shankar, J. T. Parish. "Creating New Markets through Service Innovation,” Sloan Management Review, Vol. 47, No. 2, 2006, pp. 56-63.

[9] L. Rubalcaba, G. Gallego and P. D. Hertog, "The Case of Market and System Failures in Service Innovation,” Service Industries Journal, Vol. 30, No. 4, 2010, pp. 549-566. http://dx.doi.org/10.1080/02642060903067571

[10] J. Tidd, J. Bessant and K. Pavitt, "Managing Innovation: Integrating Technological, Market and Organizational Change,” 3rd Edition, John Wiley \& Sons, Chichester, 2005.

[11] E. J. Nijssen B. Hillebr, P. Vermeulen and R. Kemp. "Exploring Product and Service Innovation Similarities and Differences," International Journal of Research in Marketing, Vol. 23, No. 3, 2006, pp. 241-251. http://dx.doi.org/10.1016/j.ijresmar.2006.02.001

[12] C. M. Froehle and A. V. Roth, "A Resource-Process Framework of New Service Development," Production and Operations Management, Vol. 16, No. 2, 2007, pp. 169188.

http://dx.doi.org/10.1111/j.1937-5956.2007.tb00174.x

[13] C. Storey and D. Kelly, "Measuring the Performance of New Service Development Activities,” The Service Industries Journal, Vol. 21, No. 2, 2001, pp. 71-90. http://dx.doi.org/10.1080/714005018

[14] R. Adams and R. B. Phelps. "Innovation Management Measurement: A Review,” International Journal of Management Reviews, Vol. 8, No. 1, 2006, pp. 21-47. 
http://dx.doi.org/10.1111/j.1468-2370.2006.00119.x

[15] P. J. Batt and S. Purchase, "Managing Collaboration within Networks and Relationships,” Industrial Marketing Management, Vol. 33, No. 3, 2004, pp. 169-174. http://dx.doi.org/10.1016/j.indmarman.2003.11.004

[16] G. Lorenzoni and A. Lipparini. "The Leveraging of Interfirm Relationships as a Distinctive Organizational Capacity: A Longitudinal Study,” Strategic Management Journal, Vol. 20, No. 4, 1999, pp. 317-328. http://dx.doi.org/10.1002/(SICI)1097-0266(199904)20:4< 317::AID-SMJ28>3.0.CO;2-3

[17] J. L. Johnson and R. S. Sohi, “The Development of Interfirm Partnering Competence: Platforms for Learning, Learning Activities, and Consequences of Learning," Journal of Business Research, Vol. 56, No. 9, 2003, pp. 757-766. http://dx.doi.org/10.1016/S0148-2963(01)00260-0

[18] F. Selnes and J. Sallis, "Promoting Relationship Learning," Journal of Marketing, Vol. 67, No. 3, 2003, pp. 80-95. http://dx.doi.org/10.1509/jmkg.67.3.80.18656

[19] L. Y. Li. "Relationship Learning at Trade Shows: Its Antecedents and Consequences," Industrial Marketing Management, Vol. 35, No. 2, 2006, pp. 166-177. http://dx.doi.org/10.1016/j.indmarman.2005.03.006

[20] C. Y. Baldwin and K. B. Clark, "Design Rules: The Power of Modularity,” MIT Press, Cambridge, 2000.

[21] F. Bougrain, B. Haudeville. "Innovation, Collaboration and SMEs. Internal Research Capacities”, Research Policy, Vol. 31, No. 5, 2002, pp. 735-747. http://dx.doi.org/10.1016/S0048-7333(01)00144-5

[22] G. Ahuja, "Collaboration Networks, Structural Holes, and Innovation: A Longitudinal Study," Administrative Science Quarterly, Vol. 45, No. 3, 2000, pp. 425-456. http://dx.doi.org/10.2307/2667105

[23] A. Grandori and G. Soda. "Inter-Firm Networks: Antecedents, Mechanisms and Forms," Organization Studies, Vol. 16, No. 2, 1995, pp. 183-214 http://dx.doi.org/10.1177/017084069501600201

[24] P. Almeida and B. Kogut, "Localization and Knowledge and the Mobility of Engineers in Regional Networks," Management Science, Vol. 45, No. 7, 1999, pp. 905-917. http://dx.doi.org/10.1287/mnsc.45.7.905

[25] K. Eisenhardt and C. Schoonhoven. "Resource-Based View of Strategic Alliance Formation: Strategic and Social Effects in Entrepreneurial Firms," Organization Science, Vol. 7, No. 2, 1996, pp. 136-150. http://dx.doi.org/10.1287/orsc.7.2.136

[26] Y. S. Chen, M. J. Lin and C. H. Chang, "The Influence of Intellectual Capital on New Product Development Performance-the Manufacturing Companies of Taiwanas as an Example," Total Quality Management \& Business Excellence, Vol. 17, No. 10, 2006, pp. 1323-1339. http://dx.doi.org/10.1080/14783360601058979

[27] J. P. Cannon and W. D. J. Perreault, "Buyer-Seller Relationships in Business Markets," Journal of Marketing Research, Vol. 36, No. 4, 1999, pp. 439-460. http://dx.doi.org/10.2307/3151999

[28] C. Grönroos, “Service Management and Marketing,” John Wiley \& Sons, New York, 2000.

[29] M. M. Crossan, W. L. Henry and E. W. Roderice, “An Organizational Learning Framework: From Intuition to Institution," Academy of Management Review, Vol. 24, No. 3, 1999, pp. 522-537.

[30] J. P. Walsh and G. R. Ungson, “Organizational Memory,” The Academy of Management Review, Vol. 16, No. 1, 1991, pp. 57-91

[31] J. S. Armstrong and T. S. Overton, "Estimating NonResponse Bias in Mail Surveys," Journal of Marketing Research, Vol. 14, No. 8, 1977, pp. 396-402. http://dx.doi.org/10.2307/3150783

[32] S. F. Slater and J. C. Narver, "Market Orientation and the Learning Organization,” Journal of Marketing, Vol. 59, No. 3, 1995, pp. 63-74. http://dx.doi.org/10.2307/1252120

[33] C. M. Fiol and M. A. Lyles, “Organizational Learning,” Academy of Management Review, Vol. 10, No. 4, 1985, pp. 803-813. 